\title{
Estimation of entropy generation by heat transfer from a liquid in an enclosure to ambient
}
D. Rakshit ${ }^{1}$
R. Narayanaswamy ${ }^{2}$
K. P. Thiagarajan ${ }^{3}$

(Received 11 March 2010; revised 11 March 2011)

\begin{abstract}
This study outlines the estimation of entropy generation of a stored liquid-vapour combination. A salient feature of the present study is the incorporation of a separated flow model for the calculation of entropy generated by a diabatic two phase system. Equations of state corresponding to different thermodynamic equilibria are used for these calculations. Two distinct expressions are proposed for the determination of the total entropy generated by the diabatic saturated two phase system that comprise liquid and ullage regions. The dissipative energy losses in various liquid-ullage systems is quantified through the derived mathematical relations obtained for the overall entropy generated by the system. These developed expressions form the basis of an experimental determination of the entropy generation rate. A parametric study on temperature influencing entropy generation has been performed in the context of different thermal transport mechanisms.
\end{abstract}

http://anziamj.austms.org.au/ojs/index.php/ANZIAMJ/article/view/2618 gives this article, (c) Austral. Mathematical Soc. 2011. Published March 29, 2011. ISSN 1446-8735. (Print two pages per sheet of paper.) Copies of this article must not be made otherwise available on the internet; instead link directly to this URL for this article. 
The influence of fill levels on entropy generation was also analysed by considering a low and an intermediate filling ratio. The study concluded the influence of central zone of thermodynamic equilibrium with maximum wall convection and minimum concentration gradient on the overall entropy generated by the system.

\section{Contents}

1 Introduction

C853

2 Mathematical Formulation

C856

2.1 Entropy calculation of two phase ullage region . . . . . C C857

2.2 Entropy calculation of diabatic saturated two phase liquid C857

3 Experimental set up

C861

4 Results and Discussion

C862

4.1 Validation . . . . . . . . . . . . . . . . . C862

5 Conclusions

C868

A Nomenclature

C870

References

C871

\section{Introduction}

Mass transfer augmentation techniques provide a simple and economical method of altering the overall thermal performance of any two phase heat exchanging device. In recent years mass transfer enhancement concepts have advanced significantly. From complex boiling phenomena to storage of highly thermodynamically unstable liquids, studies of mass transfer mechanism of a 
stored liquid in conjunction with its thermodynamic features have become inevitable. The basic objective of any mass transfer augmentation technique is to enhance the thermal performance of the system by increasing the surface mass transfer coefficient relative to the mass transfer coefficient that characterises the base mass transfer.

The main drawback of attaining this objective is associated with the thermodynamic irreversibility of the system. In spite of achieving the highest possible mass transfer from the system, sometimes the thermodynamic efficiency of the system remains less than optimal. The main factor which deals with thermodynamic irreversibility of a system is the entropy generated by a system when augmentation of mass transfer takes place. Although the foundations of knowledge of entropy production goes back to Clasius' and Kelvin's studies on the irreversible aspects of the second law of thermodynamics, the approach to incorporate its viability in the study of heat and mass transfer is relatively new. The two prime factors which make the entropy analysis of a system significant are (i) heat transfer across a finite temperature gradient, and (ii) the viscous effects of the fluid flow. The drawback of the entropy generated by the system is the reduction in the available energy of the system.

Bejan [1] proposed to deal with the heat transfer and entropy generated by the systems unilaterally, by considering fundamental convective heat transfer situations. The four basic flow situations which were analyzed under this study were: pipe flow, boundary layer over plate, single cylinder in cross flow and flow in the entrance region of a rectangular duct. Later, Bejan [2] proposed an optimum Reynolds number for pipe flow leading to the minimum entropy generation rate under fixed heat duty and flow rate. Sarangi and Chowdhury [3] analysed entropy generation in a counter flow heat exchanger and derived expressions in terms of non-dimensional parameters. The study derived the expression for entropy production of an ideal heat exchanger with a balanced capacity rate that matched closely with exact calculations. Nag and Mukherjee [4] studied the effect of various duty parameters on the thermodynamic behaviour of a convecting duct. From this analysis, it became clear that generation of entropy destroys the 
available work of a system and therefore it made good engineering sense to focus on the irreversibility of heat. Bejan [5] did an extensive review on the entropy generation minimisation technique of flow geometry through various engineering flow systems. He observed that design improvements are registered by spreading imperfections via flow resistance through the system. Zimparov [6] came up with an estimation of enhanced surfaces taking into consideration the irreversibility associated with heat transfer and fluid friction characteristics of a thermodynamic system. This general evaluation criteria added new information to Bejan's entropy generation minimisation technique. Recently, Abbassi [7] performed a second law analysis of a uniformly heated micro channel heat sink using Darcy's equation for porous medium flow. This is an innovative approach where second law optimisation was utilised in a modern fluid transport setting.

These studies mainly highlight the estimation of entropy generation in a single phase flow with no attention to the local entropy generation of two phase flow. A theory of two phase flow entropy generation was attempted by Collado [8] through the development of an expression for entropy based boiling curve for sub-cooled flow boiling. This work was based on the classical 1D entropy formulation for a steady boiling flow. Although this was a novel attempt to incorporate two phase flow in an entropy minimisation study, it did not consider the entropy generated by pressure drop and thus cannot be applied to flow boiling phenomenon of mini and micro channels. Besides, the specific contributions by heat transfer, pressure drop and phase change to entropy generation have not been explicitly expressed. In contrast to this Vargas and Bejan [9] estimated the irreversibility generated by two streams of fluids passing through a heat exchanger giving an optimal ratio between the stream mass flow rates.

From this discussion, it is evident that most studies on thermodynamic optimisation are based on entropy minimisation of single phase flow systems. No significant contribution has been made for the local entropy generation of diabatic, saturated, two phase flow. Besides, for a liquid stored in a container the concept of entropy generation needs to be studied in conjunction with its 


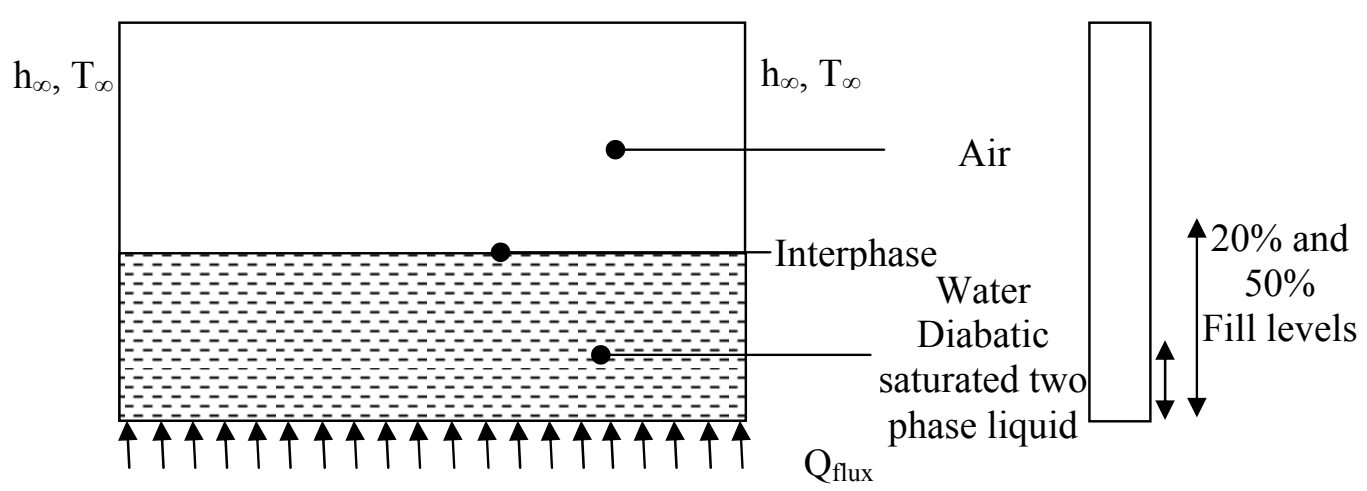

FiguRE 1: Schematic of two phase liquid and ullage with ambient conditions.

two phase ullage region. The present study is an attempt in this direction, in which a partially filled rectangular container subjected to external natural convection is studied to estimate the overall entropy generated with both an open lid and a closed lid system.

\section{Mathematical Formulation}

The system consists of a rectangular storage tank partially filled with water, subject to natural convection of air in and around the system. The overall estimation of entropy is made by aggregating the entropy generated by the diabatic saturated two phase liquid (water) and the entropy generated by the two phase ullage region at different temperatures for an open top and closed top system. Figure 1 shows the schematic of the liquid storage system explaining the physical phenomenon of two phase diabatic saturated liquid along with two phase ullage. 


\subsection{Entropy calculation of two phase ullage region}

The energy and mass conservation of a diabatic saturated two phase flow is dealt with in a simple but realistic manner using a separated flow model approach which assumes that both liquid and vapour phases travel at the same velocity. From classical thermodynamics, the vapour quality $(x)$, when represented in terms of mass flow rate $(\dot{m})$ along with two phase enthalpy $\left(h_{\mathfrak{t p}}\right)$ and entropy $\left(s_{\mathrm{tp}}\right)$ generated by the system, are

$$
\begin{aligned}
& x=\frac{\dot{\mathrm{m}}_{v}}{\dot{\mathrm{m}}_{v}+\dot{\mathrm{m}}_{\mathrm{l}}}, \\
& \mathrm{h}_{\mathrm{tp}}=x \mathrm{~h}_{v}+(1-x) \mathrm{h}_{\mathrm{l}}, \\
& \mathrm{s}_{\mathrm{tp}}=x \mathrm{~s}_{v}+(1-x) \mathrm{s}_{\mathrm{l}},
\end{aligned}
$$

where subscript $v$ and $l$ refer to vapour and liquid phases respectively. Equations (1)-(3) form the basis of the calculation of entropy generated by the two phase ullage region.

\subsection{Entropy calculation of diabatic saturated two phase liquid}

We estimate of entropy generation by the diabatic saturated flow by applying the second law of thermodynamics to a control volume of length $\mathrm{d} z$ as shown in Figure 2:

$$
\mathrm{d} \dot{s}^{\prime} \mathrm{d} z=\mathrm{d}\left(\dot{\mathrm{m}_{v}} \mathrm{~s}_{v}+\dot{\mathrm{m}}_{l} \mathrm{~s}_{l}\right)-\frac{\delta \dot{\mathrm{Q}}}{\mathrm{T}_{w}}
$$

where $d \dot{s}^{\prime}$ is the entropy generation rate per unit length, $\delta \dot{Q}$ corresponds to the heat rate applied to the control volume, and $\mathrm{T}_{w}$ is the wall temperature which is assumed to be the temperature of the system boundary. Steam is a pure substance undergoing an infinitesimal reversible process of pressure change at constant volume $v_{\text {tp }}$. Invoking the TdS equation [10] for steam,

$$
\mathrm{dh}_{\mathrm{tp}}=\mathrm{T}_{\mathrm{sat}} \mathrm{d} s_{\mathrm{tp}}+v_{\mathrm{tp}} \mathrm{dp} \text {. }
$$


$\mathrm{dz}$

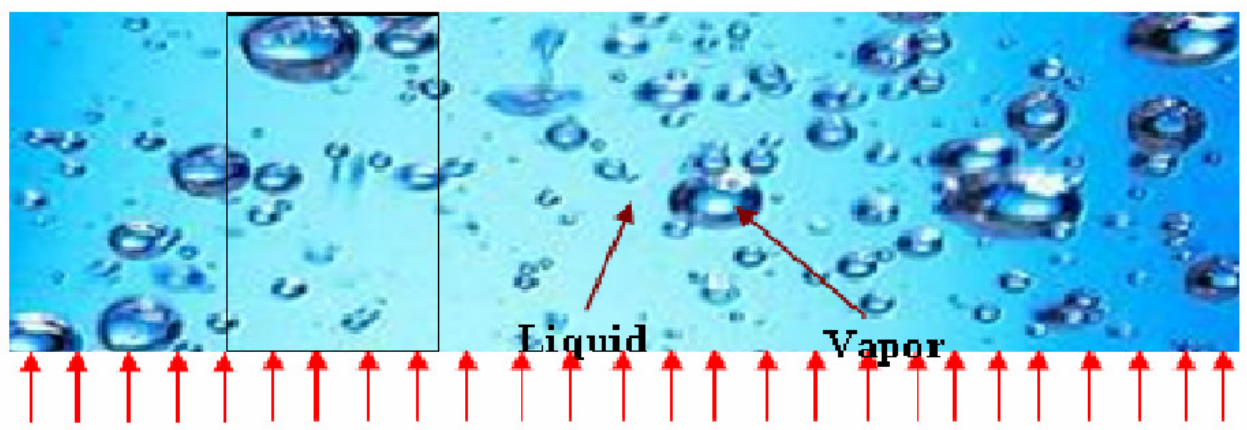

\section{Heat flux}

Figure 2: Schematic of diabatic saturated two phase liquid in stored container.

Since the entropy of steam (two phase) is an extensive property, its rate of change is expressed as the sum of the rates of change of entropy of the vapour and liquid phases that constitute the steam:

$$
\dot{\mathrm{m}}_{\mathrm{t}} \mathrm{d} s_{\mathrm{tp}}=\mathrm{d}\left(\dot{\mathrm{m}}_{v} \mathrm{~s}_{v}+\dot{\mathrm{m}}_{\mathrm{l}} \mathrm{s}_{\mathrm{l}}\right) .
$$

Substituting the values of equations (5) and (6) in equation (4) we obtain

$$
\mathrm{d} \dot{s}^{\prime} \mathrm{d} z=\frac{\dot{\mathrm{m}}_{\mathrm{t}}}{\mathrm{T}_{\mathrm{sat}}} \mathrm{dh} \mathrm{t}_{\mathrm{tp}}-\frac{\dot{\mathrm{m}}_{\mathrm{t}} \nu_{\mathrm{tp}}}{\mathrm{T}_{\mathrm{sat}}} \mathrm{dp}-\frac{\delta \dot{\mathrm{Q}}}{\mathrm{T}_{w}} .
$$

Assuming the air water system to be at constant pressure at a particular temperature with negligible kinetic energy and gravity terms, the first law of thermodynamics, when applied to liquid and ullage region, gives

$$
\frac{\delta \dot{\mathrm{Q}}}{\dot{\mathrm{m}}_{\mathrm{t}}}=\mathrm{d}\left(\mathrm{h}_{\mathrm{tp}}\right)=\mathrm{h}_{\mathrm{l} v} \mathrm{~d} x+x \mathrm{dh}_{v}+(1-x) \mathrm{dh}_{\mathrm{l}} .
$$

Substituting equation (8) in (7) we have 


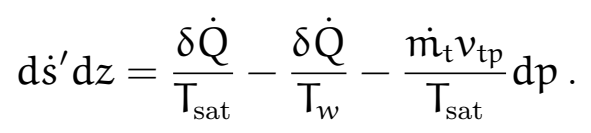

This expression estimates the overall entropy generated by a system subjected to any thermodynamic change. As our study deals with the estimation of diabatic saturated flow entropy subject to phase change, we express the wall temperature of the container in terms of liquid saturation temperature $\left(\Delta \mathrm{T}=\mathrm{T}_{w}-\mathrm{T}_{\mathrm{sat}}\right)$. This, when incorporated in equation (9), gives

$$
\mathrm{d} \dot{\mathrm{s}}^{\prime}=\frac{\delta \dot{\mathrm{Q}}}{\mathrm{d} z}\left[\frac{\Delta \mathrm{T}}{\mathrm{T}^{2}{ }_{\mathrm{sat}}\left(1+\Delta \mathrm{T} / \mathrm{T}_{\mathrm{sat}}\right)}\right]+\frac{\dot{\mathrm{m}}_{\mathrm{t}} v_{\mathrm{tp}}}{\mathrm{T}_{\mathrm{sat}}}\left(-\frac{\mathrm{dp}}{\mathrm{d} z}\right) .
$$

The ratio of $\left(\Delta T / T_{\text {sat }}\right)$ is neglected as the degree of superheat of the walls will be much less compared to the saturation temperature of the liquid ( $373 \mathrm{~K}$ for water at one atmosphere pressure). The heat input to the system estimates the overall increase in the heat content of the system along with the convective heat losses taking place from the system. Thus, assuming a constant perimeter $\mathrm{P}$ of the tank with respect to $z$ (as shown in Figure 2) when the heat content of the system is estimated,

$$
\mathrm{q}=\mathrm{h} \Delta \mathrm{T}=\frac{\delta \dot{\mathrm{Q}}}{\mathrm{d} z \mathrm{P}}
$$

Substituting equation (11) in equation (10) neglecting the ratio of $\left(\Delta \mathrm{T} / \mathrm{T}_{\mathrm{sat}}\right)$, the entropy of diabatic saturated flow is

$$
\mathrm{d} \dot{\mathrm{s}}^{\prime}=\frac{\mathrm{q}^{2} \mathrm{P}}{\mathrm{hT}^{2} \mathrm{sat}}+\frac{\dot{\mathrm{m}}_{\mathrm{t}} v_{\mathrm{tp}}}{\mathrm{T}_{\mathrm{sat}}}\left(-\frac{\mathrm{dp}}{\mathrm{d} z}\right)
$$

The first term of the right-hand side corresponds to the entropy generated due to heat transfer and the second term of right-hand side corresponds to entropy generated due to pressure drop. Here $h$ is the wall heat transfer coefficient calculated using the vertical wall Nusselt number $(\mathrm{Nu}=h l / k)$ correlation suggested by Rohsenow et al. [11]:

$$
\mathrm{Nu}=0.59(\mathrm{Gr} \operatorname{Pr})^{0.25}
$$




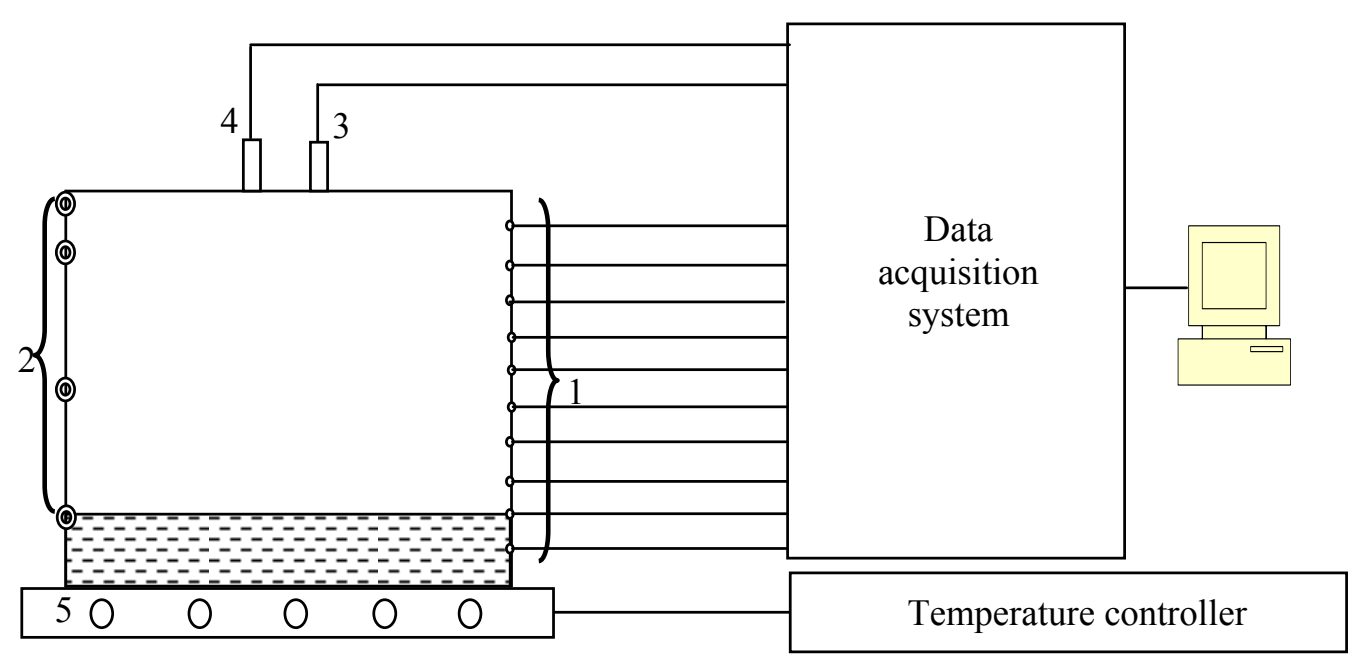

Figure 3: Schematic set-up of the test rig: 1. Thermocouples, 2. Conductivity probe at various test fill levels and top, 3. Humidity sensing probe, 4. Pressure transducer for measuring ullage pressure, 5. Cartridge heaters.

where Gr is the Grashof number which quantifies the natural convection heat loss from the system, and Pr is the Prandtl number of the fluid. Since the pressure drop contribution of the generated entropy is negligible in our case with constant ullage pressure of stationary tank, the total entropy generated by the system is the sum of the entropy generated by the diabatic saturated flow and the entropy generated by the two phase ullage. This is obtained by combining equations (3) and (12):

$$
s=x s_{v}+(1-x) s_{l}+\frac{q^{2} P}{h T^{2} \text { sat }} .
$$


TABLE 1: Range of parameters.

\begin{tabular}{cll}
\hline S. No & Parameters & Range \\
\hline 1 & Fluid & Water - Air system \\
2 & Water Temperature & $20-45^{\circ} \mathrm{C}$ \\
3 & Ambient Temperature & $18-19^{\circ} \mathrm{C}$ \\
4 & Fill level of total height & $20 \%, 50 \%$ \\
\hline
\end{tabular}

TABLE 2: Comparison of the heat transfer coefficients.

\begin{tabular}{cccc}
\hline S. No & Temperature diff. & $h_{\text {calculated }}\left(\mathrm{W} / \mathrm{m}^{2} \mathrm{~K}\right)$ & $\mathrm{h}_{\text {literature }}\left(\mathrm{W} / \mathrm{m}^{2} \mathrm{~K}\right)$ \\
\hline 1 & 10 & 9615.38 & 13236.22 \\
2 & 11 & 8741.25 & 7426.98 \\
3 & 12 & 8012.82 & 9642.24 \\
4 & 14 & 6868.13 & 8409.02 \\
\hline
\end{tabular}

\section{$3 \quad$ Experimental set up}

The experiments were carried out in a thermodynamically controlled system as shown in Figure 3. The system consists of a Plexiglass tank of dimension $260 \mathrm{~mm} \times 180 \mathrm{~mm} \times 50 \mathrm{~mm}$ heated at the bottom. The system was heated in a controlled environment with a temperature controller. To measure the temperature of the fluid, interphase and the ullage contained in the tank nine equally spaced $k$-Type thermocouples having a measurement accuracy of $\pm 0.2 \%$ were used. To estimate the convective heat losses through the walls, four equally spaced thermocouples were placed on the outer side of each wall of the tank. These thermocouples monitored the elevated temperatures of the wall with respect to the ambient temperature and in turn were used to estimate the heat losses. The top plexiglass consists of two slots having arrangements to measure the ullage pressure and relative humidity of the ullage as required, measuring the entropy of the ullage. The details of the experimental setup were described by Rakshit et al. [12]. We estimated entropy for a range of temperatures and two filling levels as shown in Table 1. 


\section{Results and Discussion}

\subsection{Validation}

The experiment was designed such that the heat and mass transfer phenomena of the two phases could be studied by changing the temperature. The present experimental setup was validated for various boiling regimes through an asymptotic mode of validation [13]. In this experiment water was heated above room temperature in steps, first to reach its saturated temperature and further beyond its saturation. The heat flux provided for heating was utilised to calculate the heat transfer coefficients of various boiling regimes. This was done using the classical correlation of Rohsenow and Jakob for nucleate boiling [14] as in

$$
\begin{aligned}
& \frac{\mathrm{Q}}{\mathrm{A}}=\mu_{\mathrm{f}} \mathrm{h}_{\mathrm{fg}}\left[\frac{g\left(\rho_{\mathrm{f}}-\rho_{\mathrm{g}}\right)}{\sigma}\right]^{0.5}\left[\frac{\mathrm{C}_{\mathrm{pf}} \Delta \mathrm{t}}{\mathrm{C}_{\mathrm{sf}} \mathrm{h}_{\mathrm{fg}} \operatorname{Pr}_{\mathrm{f}}{ }^{1.7}}\right]^{3}, \\
& \mathrm{~h}=1.54\left(\frac{\mathrm{Q}}{\mathrm{A}}\right)^{0.75}=5.58(\Delta \mathrm{T})^{3} \mathrm{~W} / \mathrm{m}^{2} \mathrm{~K} .
\end{aligned}
$$

All thermo-physical properties of the fluids were calculated from steam tables of Liley [15] . The heat transfer coefficients as obtained from the present experimental setup are tabulated in Table 2. The values of the heat transfer coefficients are comparable with those obtained through the correlations present in the literature within the error limits of a boiling experiment. The detailed validation procedure of the experimental setup was described by Rakshit et al. [12].

Figure 4 shows the transient temperature history for the bulk, interphase and ullage region of tank at $20 \%$ filling level for both closed and open systems. Irregular time dependent periodic spikes were observed for all the measured temperatures at all fill levels. After reaching a constant level the temperature of the liquid showed some undulations with a periodicity of about seven cycles per hour. Unlike the ullage temperature this wavy pattern of the liquid 
temperature was found to be repeatable for all sets of experiments. The slopes of the spikes were similar through the entire process of heating. The temperature rise refers to the bulk capacitance heat gain of the water by the heater and the temperature drop corresponds to the switch ofF of the thermostat regulating the heater [14]. The variation was consistent for all the temperature levels and even for the entire duration of the experiment. The difference in temperature response of the liquid and the ullage is due to the difference of their thermal inertias. This difference in the temperature levels of liquid and vapour phase also forms the basis of the difference in entropy generation rate of the two phases. The entropy of the system was calculated at each step of system equilibrium with the environment.

The entropy generated by the system was determined using equation (14). The datum thermophysical properties of water and steam as described above were taken from Liley [15] with the intermediate temperature properties being calculated through the empirical correlations obtained by regression analysis of the best fit data. Figures 5 and 6 show the variation of heat transfer coefficient of the tank walls with temperature by considering the heat loss across the front and side walls. These heat transfer coefficients were calculated using the correlation suggested for vertical wall heat transfer coefficient by equation (13). At lower temperature the heat transfer coefficient for both open and closed system increased rapidly with an increase in temperature, but after attaining a temperature of $30^{\circ} \mathrm{C}$ the slope tended to change with the heat transfer coefficient following an asymptotic trend.

Figure 7 shows the variation of total entropy generated per unit volume by the saturated diabatic liquid and the two phase ullage with temperature at two different fill levels with and without the top cover. The entropy generated per unit volume at higher temperature is appreciably higher than its lower fill level counterpart. This considerable hike in the entropy generation occurs because of the entropy contributed by the ullage region. This becomes clear from Figure 8 which shows the variation of the entropy generated per unit volume of the ullage with temperature for closed systems. In terms of the two phase physics, we explain this predominant increase of entropy generation in 


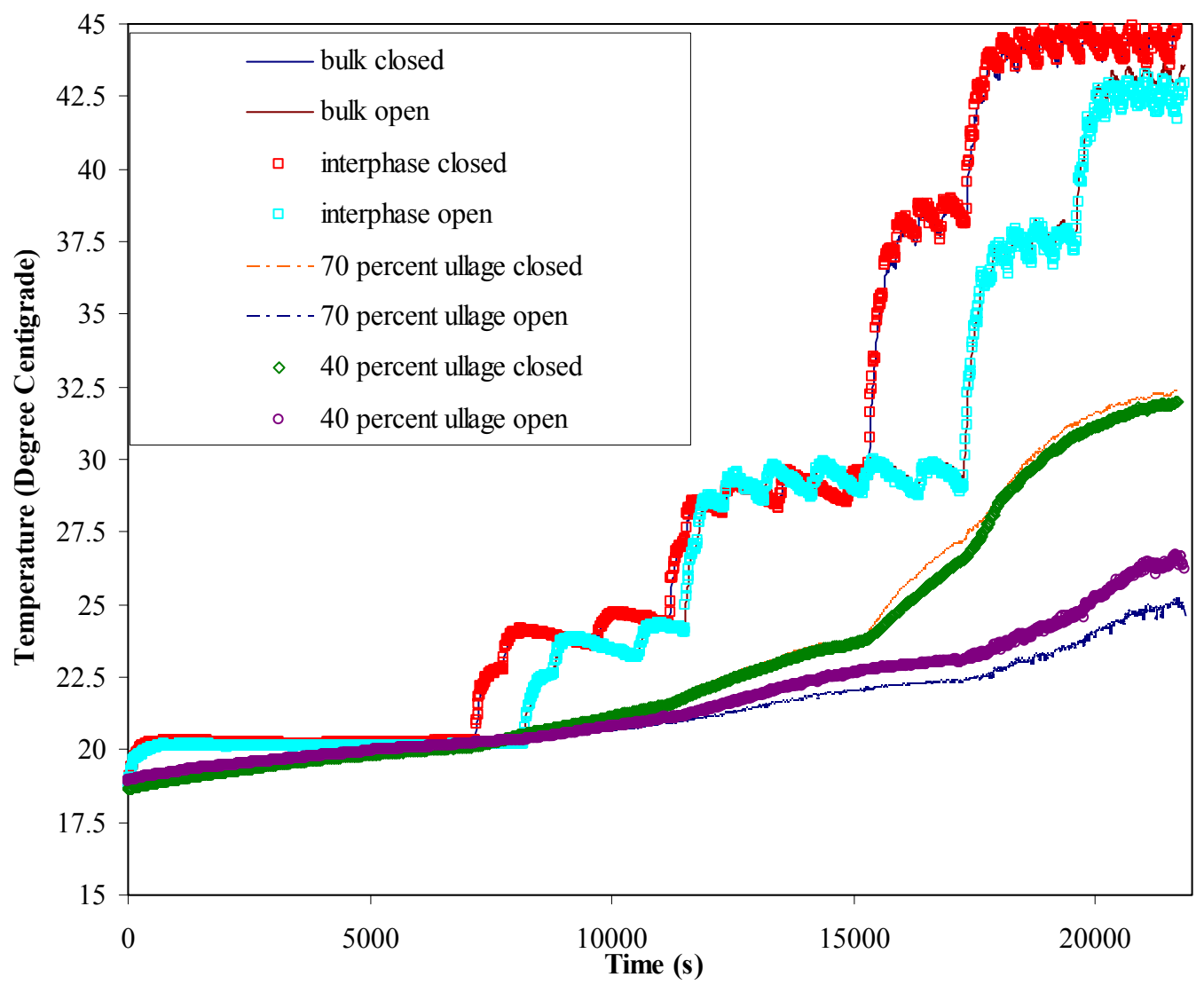

Figure 4: Transient temperature history for $20 \%$ filling level with step increase of temperature. 


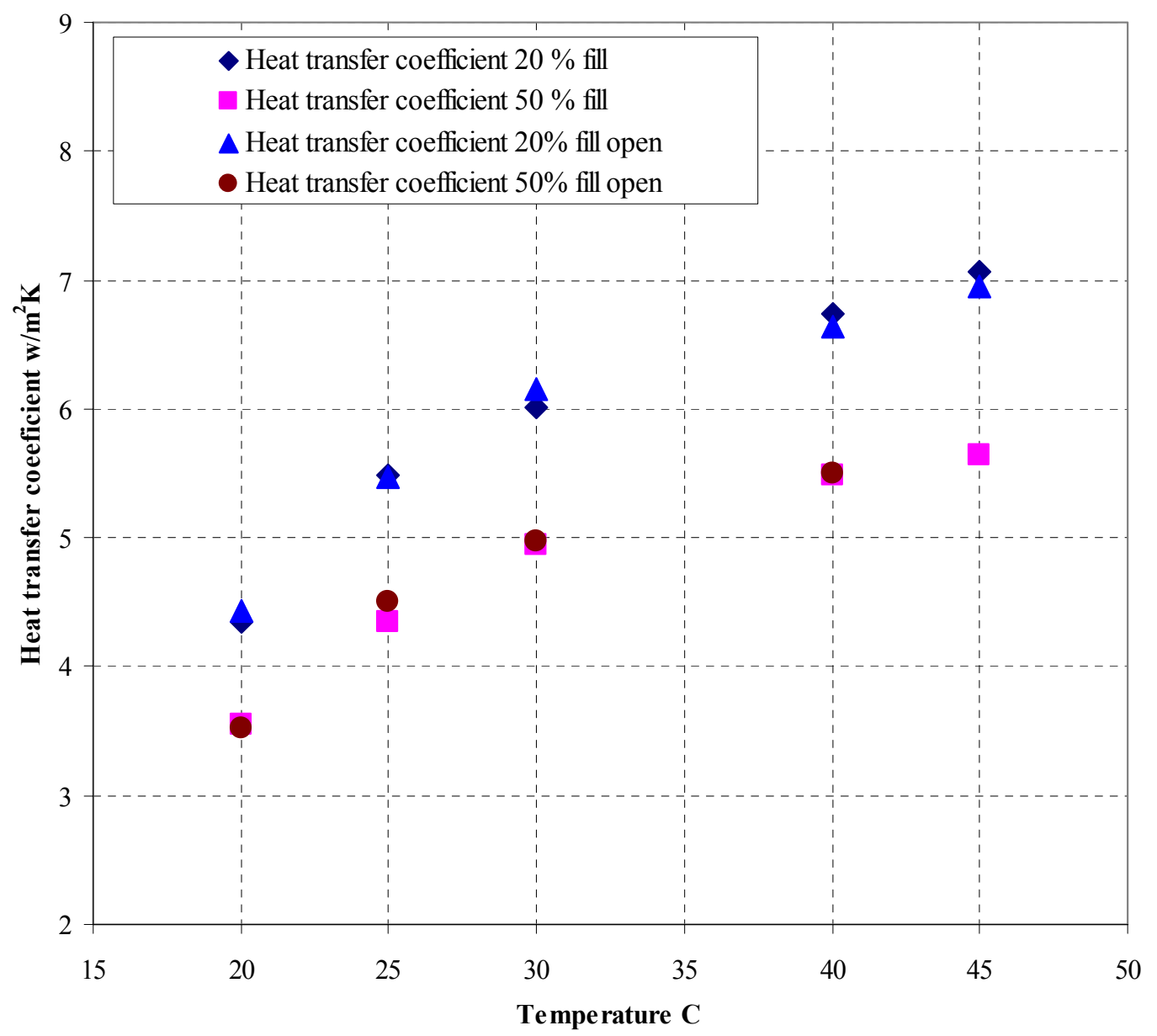

FiguRE 5: Variation of heat transfer coefficient across the front wall with temperature. 


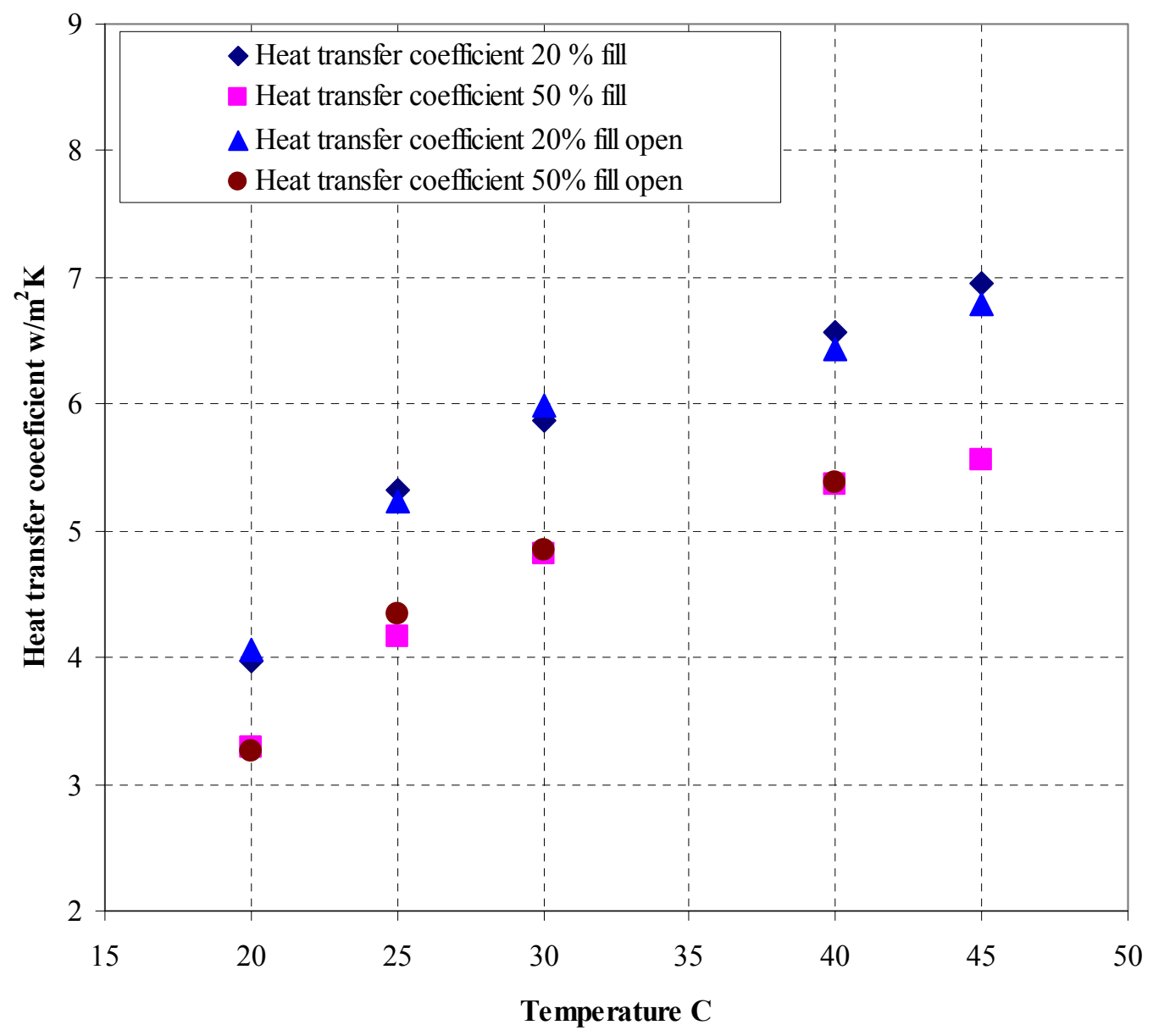

FiguRE 6: Variation of heat transfer coefficient across the side wall with temperature. 


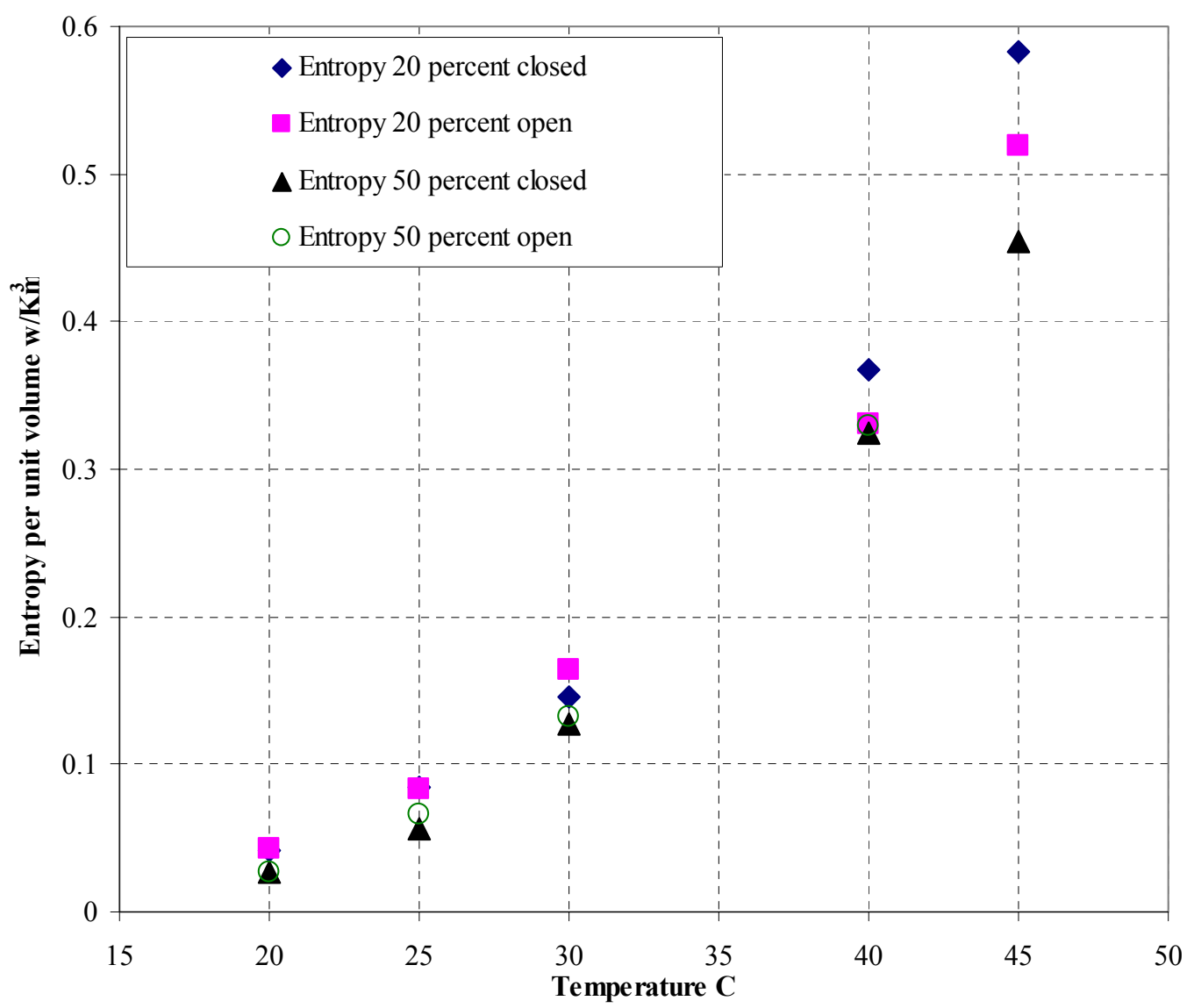

FiguRE 7: Variation of total entropy per unit volume with temperature. 
the ullage region by the Stefan phenomenon that takes place at the core of the ullage region with convective heat and mass transfer playing a vital role near the walls. The height of this zone is about $7 \mathrm{~cm}$ and $5 \mathrm{~cm}$ above the stratified layer for $20 \%$ filling level and $50 \%$ filling level respectively. This zone is coupled between the stratified nano layer zone and the top wall zone where heat and mass transfer is predominantly by conduction. Our proposition is in good agreement with findings of Malyshev and Zlobin [16].

\section{Conclusions}

We considered the mathematical modelling and the experimental determination of total entropy generated by a system consisting of a saturated diabatic two phase liquid along with two phase ullage using the first principle of separated flow model. The entropy was estimated at two fill levels and varying fluid temperatures. The heat transfer coefficient affecting the overall entropy generated by the system were also estimated. The unique findings of this study which give further insight and new knowledge to the area of second law analysis of stored liquid are the following.

1. Heat transfer coefficients of the panel losing heat to ambient are experimentally determined by calculating the overall surface temperature.

2. Entropy generation of the ullage is greater than the saturated liquid.

3. Ullage entropy which is governed by a region of mist with high humidity (dryness fraction) contributes to the maximum part of the overall entropy.

4. The central zone of mass transfer prevails for a region with maximum wall convection and minimum concentration gradient for an approximate height of $7 \mathrm{~cm}$ and $5 \mathrm{~cm}$ for $20 \%$ filling level and $50 \%$ filling level respectively. 


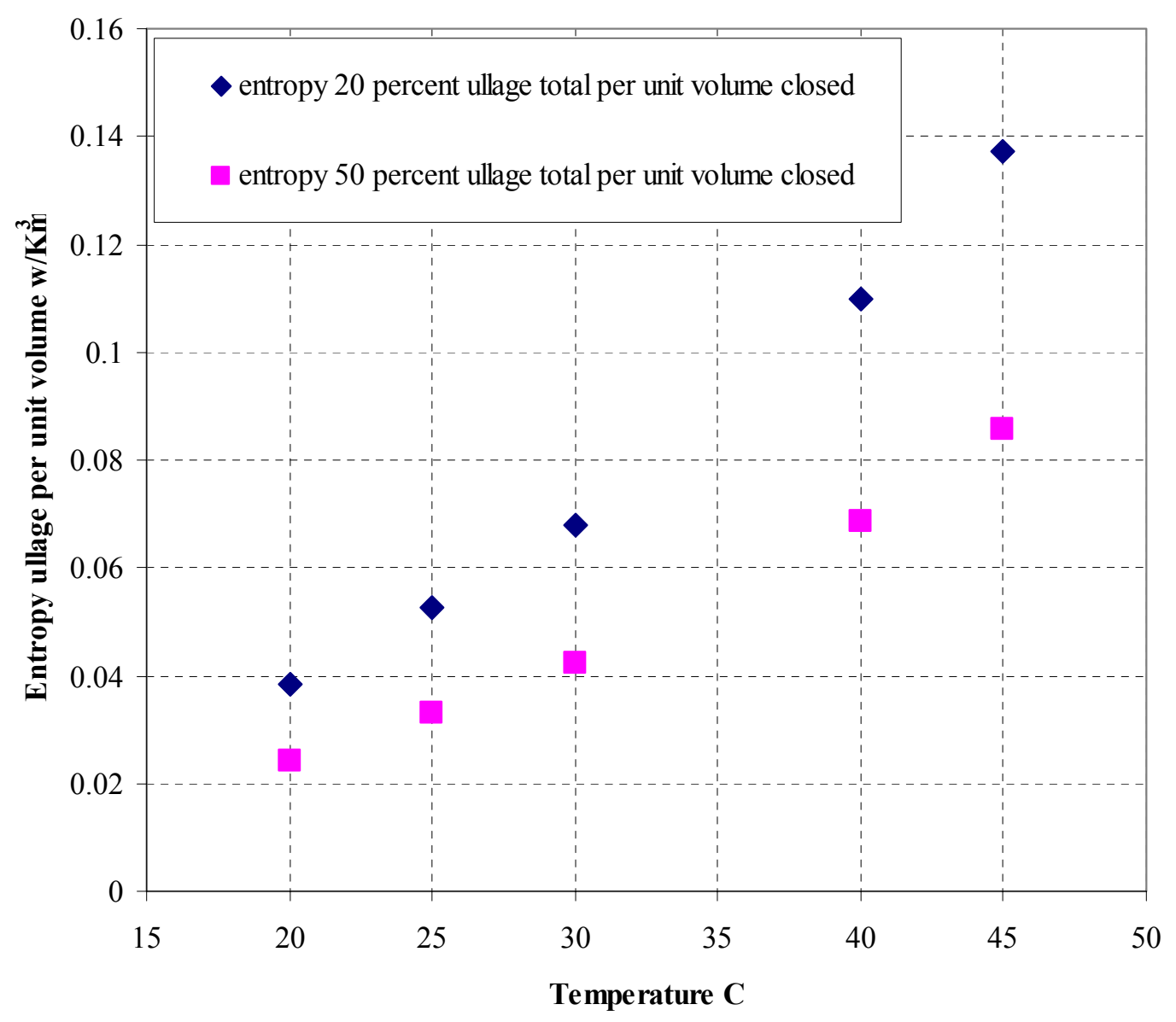

FiguRE 8: Variation of entropy per unit volume in ullage with temperature. 
Acknowledgements The study was funded by the Australian Research Council Discovery Grant DP0881447

\section{A Nomenclature}

Symbols Description

A heat transfer surface area, $\mathrm{m}^{2}$

$\mathrm{C}_{\mathrm{sf}} \quad$ surface fluid constant

Gr Grashof number, $g \beta \Delta \pi^{3} \rho^{2} / \mu^{2}$

g acceleration due to gravity, $\mathrm{m} / \mathrm{s}^{2}$

$\mathrm{h} \quad$ convective heat transfer coefficient, $\left(\mathrm{W} / \mathrm{m}^{2} \mathrm{~K}\right)$

$h_{\mathrm{tp}} \quad$ two phase enthalpy, $\mathrm{J} / \mathrm{kg}$

$h_{\mathrm{fg}} \quad$ latent heat of vaporisation, $\mathrm{J} / \mathrm{kg}$

l

characteristic length of tank, $\mathrm{m}$

$k$

$\dot{\mathrm{m}}$

thermal conductivity of fluid, $\mathrm{W} / \mathrm{mK}$

$\mathrm{p}$

mass flow rate, $\mathrm{kg} / \mathrm{s}$

fluid pressure, $\mathrm{Pa}$

$\operatorname{Pr}$

Prandtl number of fluid, $v / \alpha$

$P$

$\delta \dot{\mathrm{Q}}$

perimeter, $\mathrm{m}$

$S$

heat flux applied, $\mathrm{W}$

entropy generated by system, $\mathrm{W} / \mathrm{K}$

$\dot{s}^{\prime}$

entropy generation rate per unit length, $\mathrm{W} / \mathrm{K} \mathrm{m}$

$\mathrm{T}$ temperature, $\mathrm{K}$

$\Delta \mathrm{T} \quad$ excess temperature over saturation

$z$

co-ordinate parallel to free surface of the liquid

Greek

Description

$\alpha$

$\beta$

$\mu$

thermal diffusivity, $\mathrm{m}^{2} / \mathrm{s}$

isobaric cubic expansivity of the fluid, $-\frac{1}{\rho}\left(\frac{\partial p}{\partial T}\right), K^{-1}$

dynamic viscosity of water, $\mathrm{kg} / \mathrm{ms}$

$v$

kinematic viscosity, $\mathrm{m}^{2} / \mathrm{s}$ 
$\rho \quad$ mass density of water, $\mathrm{kg} / \mathrm{m}^{3}$

$\sigma \quad$ surface tension, $\mathrm{N} / \mathrm{m}$

$\begin{array}{ll}\text { Subscripts } & \text { Description } \\ \infty & \text { ambient } \\ \mathrm{f} & \text { fluid } \\ \mathrm{g} & \text { gas } \\ v & \text { vapor } \\ \mathrm{l} & \text { liquid } \\ \mathrm{t} & \text { total } \\ \mathrm{tp} & \text { two phase } \\ v & \text { vapor } \\ \text { sat } & \text { sat }\end{array}$

\section{References}

[1] A. Bejan. A study of entropy generation in fundamental convective heat transfers. ASME J Heat Transfer, 101, 1979, 718-725. doi:10.1115/1.3451063 C854

[2] A. Bejan. Second law analysis in heat transfer. Energy, 5, 1980, 721-732. doi:10.1016/0360-5442(80)90091-2 C854

[3] S. Sarangi. and K. Chowdhury. On the generation of entropy in a counter flow heat exchanger. Cryogenics, 22, 1982, 63-65. doi:10.1016/0011-2275(82)90095-9 C854

[4] P. K. Nag and P. Mukherjee. Thermodynamic optimization of convective heat transfer through a duct with constant wall temperature. Int J. Heat and Mass Transfer, 30, 1987, 401-405. doi:10.1016/0017-9310(87)90128-1 C854 
[5] A. Bejan A thermodynamic optimization of geometry in engineering flow systems. Exergy Int. Journal, 4, 2001, 269-277. doi:10.1016/S1164-0235(01)00028-0 C855

[6] V. D. Zimparov Extended performance evaluation criteria for enhanced heat transfer surfaces: heat transfer through ducts with constant heat flux. Int J. Heat and Mass Transfer, 44, 2001, 169-180. doi:10.1016/S0017-9310(00)00074-0 C855

[7] H. Abbassi Entropy generation analysis in a uniformly heated micro channel heat sink. Energy, 32, 2007, 1932-1947. doi:10.1016/j.energy.2007.02.007 C855

[8] F. J. Collado The law of stable equilibrium and the entropy-based boiling curve for flow boiling. Energy, 30, 2005, 807-819. doi:10.1016/j.energy.2004.04.007 C855

[9] J. V. C. Vargas and A. Bejan Thermodynamic optimization of the match between two streams with phase change. Energy, 25, 2000, 15-33. doi:10.1016/S0360-5442(99)00052-3 C855

[10] P. K. Nag Engineering Thermodynamics. Tata McGraw-Hill Publishing Company Limited, 2nd Edition, 1996. C857

[11] W. M. Rohsenow, J. P. Hartnett, Y. I. Cho, Hand book of Heat Transfer. McGraw-Hill New York,3rd Edition, 1988. C859

[12] D. Rakshit, R. Narayanaswamy, T. Truong, K. P. Thiagarajan An experimental study on the interface mass transfer governing thermodynamics of stored liquids. Proceedings of the 20th National and 9th International ISHMT-ASME Heat and Mass Transfer Conference, January 4-6, 2010, Mumbai India. C861, C862

[13] C. Balaji, M. Hlling, H. Herwig Entropy generation minimization in turbulent mixed convection flows. International Communications in Heat and Mass Transfer, 34, 2007, 544-552. doi:10.1016/j.icheatmasstransfer.2007.01.015 C862 
[14] F. P. Incropera, D. P. Dewitt, T. L. Bergmen, A. S. Lavine Introduction to Heat Transfer. John Willey and Sons, 5th Edition, 2005. C862, C863

[15] P.E. Liley, Steam Tables in SI Units, private communication. School of Mechanical Engineering, Purdue University, West Lafayette, IN., 1984. C862, C863

[16] V. V. Malyshev and E. P. Zlobin Evaporation of liquid hydrocarbons in heated closed containers. Translated from Inzheneruo-Fizicheskii Zhurnal, 23, 4, 1972, 701-708. doi:10.1007/BF00835847 C868

\section{Author addresses}

1. D. Rakshit, School of Mechanical Engineering, The University of Western Australia, Crawley Australia.

mailto: dibakar@mech . uwa.edu . au

2. R. Narayanaswamy, Dept of Mechanical Engineering, Curtin University Australia. mailto:R.Narayanaswamy@curtin.edu.au

3. K. P. Thiagarajan, School of Mechanical Engineering, The University of Western Australia, Crawley Australia. mailto:krish.thiagarajan@uwa.edu.au 